Article

\title{
Multilevel Governance for Forests and Climate Change: Learning from Southern Mexico
}

\section{Salla Rantala ${ }^{1, *}$, Reem Hajjar ${ }^{2}$ and Margaret Skutsch ${ }^{3}$}

1 Institute for Natural Resources, Environment and Society, University of Eastern Finland; current affiliation: Environmental Policy Centre, Finnish Environment Institute, Helsinki 00251, Finland

2 Faculty of Forestry, University of British Columbia, Vancouver, BC, Canada V6T 1Z4; E-Mail: reem.hajjar@gmail.com

3 Centro de Investigaciones en Geografía Ambiental, Universidad Nacional Autónoma de Mexico, Morelia, CP 58190, Michoacán, Mexico; E-Mail: mskutsch@ciga.unam.mx

* Author to whom correspondence should be addressed; E-Mail: salla.rantala@ymparisto.fi; Tel.: +358-29-525-1257.

External Editor: Pablo Pacheco

Received: 12 August 2014; in revised form: 1 December 2014 / Accepted: 5 December 2014 / Published: 12 December 2014

Abstract: Reducing emissions from deforestation and forest degradation (REDD + ) involves global and national policy measures as well as effective action at the landscape scale across productive sectors. Multilevel governance (MLG) characterizes policy processes and regimes of cross-scale and cross-sector participation by multiple public and private actors for improved legitimacy and effectiveness of policy. We examine multilevel, multi-actor engagement in REDD+ planning in Quintana Roo, Mexico, to find out how local perspectives align with the national policy approach to REDD + as an integrating element of holistic rural development at territorial scale, and how current practices support procedurally legitimate MLG required to implement it. We find that there is wide conceptual agreement on the proposed approach by a variety of involved actors, in rejection of the business-as-usual sectoral interventions. Its implementation, however, is challenged by gaps in horizontal and vertical integration due to strong sectoral identities and hierarchies, and de facto centralization of power at the federal level. Continued participation of multiple government and civil society actors to contribute to social learning for locally appropriate REDD+ actions is likely to require a more balanced distribution of resources and influence across levels. Meaningfully engaging and ensuring 
the representation of local community interests in the process remains a critical challenge.

Keywords: multilevel governance; forest; climate change; REDD+; Mexico

\section{Introduction}

Mitigating climate change through reducing emissions from deforestation and forest degradation $(\mathrm{REDD}+)$ is a scale-spanning problem, requiring coordination across vertical and horizontal levels of governance. While the push and pull for REDD+ policies and interventions comes from international and national negotiations, corresponding actions need to be locally appropriate to be effective. In the policy negotiations and on the ground, efforts to conserve forests, manage forests sustainably and enhance carbon stocks through reforestation and afforestation frequently face strong competition from other potential and existing land uses. REDD+ actions also need to be legitimate, in the sense of being accepted and seen to be fair and useful, in order to ensure long-term sustainability. Achieving legitimacy and effectiveness requires the participation of civil society in various forms-local community groups, producer associations and rural cooperatives, as well as NGOs that support initiatives for the environment and development - in addition to traditional governmental players. There is an increasing recognition that REDD+ should be approached through landscape approaches that address the multiple cross-scale socio-economic and politico-environmental interactions that shape resource use and management in specific places [1-3]. This means that landscape approaches to REDD+ operate in arenas that could be characterized as those of 'multi-level governance' (MLG) $[4,5]$.

The concept of MLG, first introduced by scholars in the context of governance in the European Union [6,7], is increasingly used to describe or to examine processes and outcomes in cross-scale, multi-actor environmental governance [8,9]. Key aspects attached to MLG include the increased role and participation of non-state actors; transformation of the role of the state; understanding decision making through complex networks and negotiations in addition to hierarchically nested jurisdictions; and challenging conventional notions of accountability of democratic institutions [9,10]. Emerging cross-level and horizontal networks may represent new opportunities for diverse actors to participate in decision making concerning natural resources, engage in mutual learning and strengthen vertical and horizontal integration for more effective policies [8]. Horizontal and cross-sectoral coordination is of particular relevance for REDD+, given that the drivers of deforestation and forest degradation frequently emanate from outside the forestry sector. Enhanced vertical integration is expected to result in locally appropriate and effective actions, that is, improving the fit with local institutions and environmental conditions [11]. Furthermore, effective cross-level participation in policy formulation by a large number of stakeholders may increase the legitimacy and subsequently environmental effectiveness of the policy [12]. At the same time, it is acknowledged that the actors are embedded in existing webs of rules, resources and hierarchies, which shape their actions and influence. Power relations and institutional structures may undermine the legitimacy and effectiveness expectations of MLG by reproducing path-dependent governance processes with business-as-usual outcomes [13]. A particular concern about MLG is the potential accountability deficit associated with decision making 
influenced by loose, sometimes invisible issue networks instead of formal, democratically elected bodies [14]; who may then be held responsible for the content of policy?

In this study, we investigate the vertical and horizontal integration of multilevel planning for REDD+ strategies in Mexico. Mexico embarked early on the planning of a national REDD+ program, led by CONAFOR, the National Forestry Commission, which falls under the Ministry of Environment and Natural Resources. Since the publication of a Vision for REDD+ in 2010 [15], a draft National Strategy on REDD+ [16] has been under development and revision. Through both the Vision and the national strategy, Mexico has been spearheading an integrated approach to REDD+ as sustainable rural development, one that plans to bring improved methods of production and support to livelihoods to rural areas. Far from being a narrow, carbon-centric policy, it is described in these documents as multi-sectoral, integrating various policies and actions and requiring coordination across different government programs, particularly between agriculture and forestry. REDD + actions will be implemented within a territorial approach, in line with the national Law for Sustainable Rural Development (2001), and include activities outside the forest sector, in parallel with the global trend towards landscape approaches in REDD+. For horizontal, cross-sectoral coordination, various government ministries form a Working Group on REDD+ (Grupo de Trabajo, GT-REDD+) under the Intersectoral Commission on Climate Change. A large number of civil society actors such as NGOs, academics, other local stakeholders as well as some state governments have provided comments and inputs to the REDD+ strategy development through the national Comité Técnico Consultivo (CTC-REDD+), which started in 2010, as well as via a working group under the National Forest Council since 2013. Various states are developing their own REDD+ strategies, for which parallel structures (GT-REDD+, CTC) have been set up at the state level. This is the sub-national level envisioned for accounting for emission reductions and attributing corresponding performance-based payments [17].

In our case study of Quintana Roo state, we examine current governance practices and how these measure up to the requirements considered necessary for effective MLG for REDD+, given Mexico's broad REDD+ focus on sustainable rural development. As one of the three states participating in the Yucatán Peninsula regional climate change initiative since 2010, Quintana Roo is a site of REDD+ Early Action by CONAFOR and is developing its own state REDD+ strategy. Quintana Roo is also the first state to replicate the experience of inter-municipal associations developed for integrated watershed management in the state of Jalisco, as the Association of the Municipalities of Southern Quintana Roo (AMUSUR) was formally established in 2013. CONAFOR is promoting this model for REDD+ governance, with support from Spain, as a means of operationalizing the territorial approach [18].

Through attention to the formal structures that have been set up to support the state REDD+ strategy development, as well as the networks of REDD+ relevant information sharing, collaboration and influence by various organizational actors spanning the national, regional, state and local (municipal and community) levels, we assess the procedural legitimacy of this kind of MLG. Procedural legitimacy, consisting of participation, representation, deliberation and accountability of the various actor groups in the formal and informal REDD+ structures, is expected to shape the effectiveness of state REDD+ planning, which is considered here as the extent to which locally appropriate REDD+ actions are considered in the process. For that, we combine the assessment of procedural legitimacy of 
the REDD+ process with an interpretive analysis of the various actors' conceptualization of REDD+ and the appropriate actions to address the drivers of deforestation and forest degradation, especially as they conform to the approach proposed in the national REDD+ strategy. Thus, the research questions that the study intends to address are:

(1) How do the views of different actors participating in REDD + strategic planning at the sub-national (state) level, taking Quintana Roo as an example, align with the national policy approach to REDD+ as a broad, holistic strategy for sustainable rural development?

(2) How do the current practices of horizontal and vertical coordination in MLG support procedurally legitimate REDD+ planning to operationalize the envisioned approach? What kind of opportunities and bottlenecks are there, and with what implications for the development and implementation of locally appropriate actions?

\section{Case Study: Multilevel Governance for REDD+ in Quintana Roo, Mexico}

\subsection{Conceptual Framework}

In our exploration of horizontal and vertical coordination for REDD + planning in Quintana Roo, we employ the concept of procedural legitimacy [19] as a tool to allow us to examine the key tenets of multilevel governance as outlined above: the expectations of increased legitimacy and "fit" or local appropriateness of policy on the one hand, and the risk of compromised democratic representation and accountability, on the other. Legitimacy may be broadly understood as the acceptance of or authority granted to institutions and regimes. Procedural legitimacy, in turn, relates to the quality of political processes, such as those of REDD+ planning at the various levels, as they conform to normative principles such as inclusion, representation, deliberation, and accountability [20,21]. Following previous authors [19,21], we pay attention to two mechanisms through which procedural legitimacy may lead to improved performance of multilevel governance for REDD+:

1. Ownership on the basis of inclusive and representative participation. The inclusion of as many stakeholders as possible in policy formulation, though to varying degrees, is the norm in current development discourse. Parties to the UNFCCC have agreed to follow this principle in the development of REDD+ actions [22]. With increased duration and quality of participation, stakeholders develop an ownership over the negotiated rules and norms and are more likely to accept the costs of implementing them. This ownership is both emotional (attachment to the process and to other involved actors) as well as rational; i.e., there is an expectation that through participation, the actors will be able to access relevant information as well as make their own proposals and defend their own interests in the process. Often, participation is indirect through representatives and spokespersons. It is important that the representatives are considered sincere, legitimate and sufficiently mandated by their principals or constituencies so that the rules, if indeed negotiated by the representatives in participatory processes, are accepted also by the constituencies [19].

2. Social learning and persuasion based on deliberation. This core facet of the theories on deliberative democracy $[23,24]$ assumes that when participants to political processes have the chance to critically, freely and transparently argue for and against different policy proposals, they are more likely to accept the outcome of the negotiation and subsequently comply with it. The outcome is not 
necessarily a consensus [25], but social learning may occur as a result of being exposed to new evidence and arguments or simply recognizing that multiple points of view exist, leading the actors to redefine the situation and ultimately contributing to behavioral change [19]. However, the discursive aspects of policy processes and particularly the influence of deliberation may be undermined by entrenched power asymmetries based on differential positions of actors in the relevant formal institutional frameworks as well as resource networks [21,26,27].

An additional proposed mechanism is social control based on transparency and accountability [19,21]. The ability of stakeholders to hold decision makers to account is likely to increase their adherence to the outcomes of a rule-making process [19]. This mechanism assumes that democratic representation exists and relates to the reservation associated with MLG; if resource management decisions are influenced by issue-specific networks (e.g., multilateral REDD+ initiatives) that may even be partially invisible to the stakeholders that first and foremost depend on the resource, it will be impossible to know whom to hold accountable. While this view emphasizes the post-decisions situation, we expand our attention to the role of existing lines of accountability, access to information, and responsiveness of participants to local demands in the on-going negotiation process, discussing accountability as closely related to representation and information sharing. An important distinction is made between internal and external accountability [28]; that is, whether the participants to a planning process are principally accountable towards their own institutions, or other actors who will nevertheless be affected by the decisions.

Summing up, our focus is on the dynamics of participation, representation, deliberation and accountability shaping the procedural legitimacy of REDD+ planning and the definition of locally appropriate REDD+ actions in Quintana Roo. These dynamics are considered affected by inter-actor power relations, in which power is understood as both positional and relational: based on formal institutional positions as well as reputations and resource networks. The focus is on information as a key resource, considering its role in the deliberative processes for the social construction of discourses on appropriate REDD+ actions and the dynamics of representation and accountability.

\subsection{Data Collection and Analysis}

We primarily draw from data collected through semi-structured interviews and unstructured discussions with REDD+ organizational actors in Quintana Roo and at the regional level of the Yucatan Peninsula in November-December 2013. In order to gain insights into locally appropriate and legitimate approaches to REDD+ implementation, the interviews probed the actors' knowledge and interests in REDD+, which yielded information on their conceptualization of the problem at hand and perceptions of appropriate solutions. Our open-ended approach was based on an understanding that actor preferences are socially constructed, rooted in distinct worldviews and interests, and shaped by social interaction in the MLG system. Specific questions were asked in relation to the regional and state level REDD+ planning processes vis-à-vis the different facets of procedural legitimacy. Participant observation in REDD+ multi-actor meetings and workshops, and discussions with key informants from the government and civil society contributed to the material. 
The REDD+ actors included in the study were identified using snowball sampling, starting with an initial set of five organizational actors who have a formal role in REDD+ development at the level of the Yucatan Peninsula (the three state governments' environmental agencies, CONAFOR and a large international NGO). These actors were interviewed and asked to name organizational partners, especially those with incidence in Quintana Roo state, with whom they regularly shared REDD+ related information (including technical and conceptual information as well as information related to, e.g., opportunities to participate in REDD+ planning and implementation), collaborated in forests and climate change related activities (these activities were then discussed in depth), or thought were particularly influential for REDD+ decision making. In addition, they were asked whether there were actors that were currently not engaged in the state REDD+ process although they should be. In other words, we combined the sampling with an empirical mapping of inter-organizational networks, and the approach was realist in emphasizing the actors' perceptions of relevance [29]. The named actors constituted the first wave of interviewees, whom in turn were interviewed and asked to name their partners in the same relationships (second wave). Partners were typically named in clusters or in association with the REDD+ structures (the CTC and GT-REDD+ of Quintana Roo). The partners that are named first often have the strongest ties to the respondent or are salient in the context (high status or frequent presence in the setting) [30] (p. 15). Over $90 \%$ of the nominations referred back to the initial set of actors and those mentioned during the first wave. Considering this an indication that the most relevant organizational actors had been identified, sampling was stopped at the second wave and interviewing the first-wave actors was prioritized, including the organizational members of the CTC Q. Roo, which was frequently mentioned as an "actor". The network data for ten actors was complemented by their responses to a web-based survey launched simultaneously for another study that asked the same questions about REDD+ information exchange and influence.

No statistical formula was used to estimate the numbers of "hidden" or non-sampled actors, because the initial sampling was non-random (purposive), and the actors at different levels of governance could be expected to be very heterogeneous in terms of the numbers and type of partners. We were also more interested in the content of actor interactions based on a qualitative analysis of interview data through the procedural legitimacy lens, than in network structural properties measured through Social Network Analysis (SNA) techniques, which often require sampling complete networks. SNA was applied in this study as a complementary tool, primarily for visualizing networks. In addition, we used two specific SNA measures to detect actors in key positions to influence REDD+ planning. Normalized indegree centrality measures how often an actor has been mentioned as influential in relation to all possible nominations and is considered a good indicator of status and power [31] in the REDD+ MLG system. Indegree centrality is one of the most robust SNA measures with missing data and $90 \%$ accurate even with a 50\% sampling level [32]. Brokerage measures [33] were used to investigate which actors mediated flow of information between otherwise unconnected actors on different levels (international, national, regional, state, local). Such scale-crossing brokers may be particularly influential for the diffusion of scale-specific and place-specific knowledge and information in multilevel governance processes [34], and thus be in a position to facilitate, or block, the development of locally appropriate REDD+ actions.

Many of the organizations had direct collaborations with several local communities or ejidos, dozens or even hundreds of them if community participation in a programme administered by a 
government agency such as CONAFOR is considered a collaborative relationship. Since achieving a representative sample of all these communities was problematic within the limits of the research project, we purposively sampled member communities of two of the oldest producer organizations in Quintana Roo, SPFEQR (Quintana Roo Society of Forest Producer Communities) and OEPFZM (Community Organization of Forest Producers of the Zona Maya), each representing 8 forest producer communities. Both organizations were identified as relevant organizational actors through the snowball sampling procedure. The president of the SPFEQR was the formal forestry sector representative in the CTC Q. Roo, and the technical director of OEPFZM had temporarily held the presidency of the CTC Q. Roo. Forest producer communities were also of particular interest because the previous literature suggests them to be well-integrated with higher level governance institutions in Mexico, not to mention their relatively secure legal rights to land and forest compared to other countries [35], offering a promising base for REDD+ actions [36]. Interviews were held opportunistically with several of the elected leaders (comisariados) of the organizations' member communities (six SPFEQR members and seven OEPFZM members) as they conducted their weekly visits to the organizations' offices, to ascertain linkages of these communities to the broader networks and structures of REDD+ development as well as their conceptualization of REDD+.

Excluding the communities, the types and number of actors nominated and interviewed are presented in Table 1.

Table 1.Nominated and interviewed organizational actors.

\begin{tabular}{|c|c|c|c|}
\hline $\begin{array}{c}\text { Organizational } \\
\text { Type } \\
\end{array}$ & $N$ Nominated & $n$ Interviewed & Level of Governance \\
\hline $\begin{array}{c}\text { Federal } \\
\text { government }\end{array}$ & 8 & $5(63 \%)$ & $\begin{array}{l}\text { National, with branches at the state } \\
\text { level and operations at the local level }\end{array}$ \\
\hline State government & 5 & $4(80 \%)$ & $\begin{array}{l}\text { State (Yucatán and Campeche state } \\
\text { governments considered in Figure } 1 \\
\text { as "regional") }\end{array}$ \\
\hline $\begin{array}{l}\text { Municipal } \\
\text { government }\end{array}$ & 4 & $3(75 \%)$ & Local \\
\hline National NGO & 11 & $8(73 \%)$ & National/regional/state \\
\hline $\begin{array}{l}\text { Producer } \\
\text { organization }\end{array}$ & 8 & $4(50 \%)$ & State/local \\
\hline $\begin{array}{l}\text { Academic, } \\
\text { research }\end{array}$ & 5 & $1(20 \%)$ & State \\
\hline $\begin{array}{l}\text { International } \\
\text { NGO }\end{array}$ & 3 & $3(100 \%)$ & $\begin{array}{l}\text { International, with operations at } \\
\text { national, regional, and local levels }\end{array}$ \\
\hline Intergovernmental & 2 & $1(50 \%)$ & International \\
\hline $\begin{array}{c}\text { Foreign } \\
\text { government }\end{array}$ & 1 & 0 & International \\
\hline Total & 47 & $\begin{array}{c}26(55 \% / 76 \% \text { of the actors } \\
\text { named in } 90 \% \text { of } \\
\text { nominations made })\end{array}$ & \\
\hline
\end{tabular}




\section{Results and Discussion}

\subsection{Conceptualizing REDD+: Means to an End in Holistic Rural Development}

The most striking result of our analysis of the qualitative interview data was that there was remarkable congruence in the conceptualization of the appropriate REDD + approach by the interviewees representing various types of organizations, including federal, state and municipal governments, NGOs and producer organizations; they appeared to hold very similar views on what was really required under REDD+. Most of these actors stressed that what was needed was a (paradigmatic) change towards more environmentally-friendly and "climate-effective" production methods that were economically viable. That is, benefits for forests, climate and people would be generated by the improved practices themselves, and any REDD + payments would just be an additional reward. As summarized by an NGO interviewee:

"The vision is to achieve changes and REDD+ is one opportunity to strengthen them, but it is not an end in itself' (International NGO officer, 15 November 2013).

The view of the sub-national level actors interviewed of REDD+ as means to a much broader end beyond carbon savings and conditional payments thus coincides with that adopted in the national REDD+ policy documents [15-17]. This overlap may reflect effective promotion of the formal policy proposals by key actors, discussed in the following, or it may support the notion that the gradual drafting of the national REDD+ strategy, through a participatory process, has indeed captured inputs and concerns "from the field" [37].

Several interviewees provided detailed rationales for this conceptualization of REDD+, emphasizing first-hand experience of the challenges of implementing policy or projects aimed at increasing social and environmental sustainability in the current context. They communicated a strong conception that agriculture, and agricultural subsidies, had been and were likely to continue to be a key factor in land use change in the Yucatán Peninsula. This was seen as reinforced by the fact that the Ministry of Agriculture (SAGARPA) now enjoyed the largest allocation of the federal budget in its history, in line with the priorities of the administration of President Peña Nieto on food security and increasing the competitiveness of the agriculture sector [38]. Federal funding for forestry within the environment sector amounted to only a fraction of this (less than 10\% of SAGARPA's budget in 2014) [39]. (In comparison, scientific evidence for the impact of agricultural subsidies is not clear-cut. Some studies have found them to be a factor behind deforestation in Mexico, including the Yucatán Peninsula and Quintana Roo [40-43], although this may have been a temporary effect since the main program, PROCAMPO, issued subsidies for selected parcels of land in the late 1990s; these are still being paid but there has been very little new land admitted to the program since then. Others have found no correlation between PROCAMPO and deforestation [44]. The impact of many other agricultural policies and programs has not yet been studied. Although the drivers of deforestation and degradation (conversion of forest land to agriculture and ranching, urban expansion, over exploitation of forests for firewood and charcoal) have been explored in localized studies, the actual processes and the conditions under which they occur have hardly been investigated. In the peninsula as a whole, the expansion of pasture is thought to be one of the more important causes of deforestation, and this is 
often related to outmigration $[41,45,46]$. Areas under community forest management have been shown to have lower deforestation rates than community land under Protected Area status [47]).

Given the perceived importance and impacts of the agriculture sector, the state government and civil society actors expressed doubts about achieving successful REDD+ in the event that it continued to be de facto labeled a CONAFOR project. They stressed that the transformation towards sustainability required holistic cross-sectoral support and essentially a move away from the current business-as-usual implementation of sectoral, top-down projects, primarily consisting of the disbursement of ear-marked subsidies, which they saw as having few positive impacts on the environment or on social development. Producer organizations contributed to this view by emphasizing the high transaction costs of switching to more sustainable production (e.g., agrosilvopastoral systems) and therefore the need to create "real alternatives" for producers instead of regulation and scattered proyectitos ("little projects"). They also stated that such alternatives should be clearly linked to a market demand and developed with a business approach, building entrepreneurial capacities among the producers. Neither the "real alternative" requirement nor the business aspect had been realized, in the view of the interviewees, in the federal agencies' current interventions.

In conjunction with their conceptualization of REDD + as rural development, the interviewees considered the scope for potentially appropriate REDD+ actions broad. Recognizing that not enough was known about the dynamics of deforestation and forest degradation in the current context, thorough diagnostics and effective participation by local actors were called for to aid the development of locally effective and sustainable interventions. The civil society, state government and research actors strongly critiqued current centrally designed programs that included different blue-print options being offered to producers like a breakfast menu, for their poor fit to local realities:

"You open a call, look here guys, here is the menu, you can ask for this: fried eggs, motuleños, whatever...You choose and in one month you need to present these things and in six months the money will arrive. Once the money arrives you need to show me the results. This is an easy monitoring strategy for the government, but it is not exactly what is required" (Producer organization officer, 29 November 2013).

For example, many criticized the Special Program for the Yucatan Peninsula (PEPY), through which CONAFOR currently implements REDD+ Early Action in the peninsula [48], for following the centrally designed model.

Similarly in line with the national REDD+ policy documents and the idea of holistic support, several interviewees stressed the role of territorial planning for REDD + actions in the rural development framework. There were, however, differences of opinions about the appropriate scale. The state authorities saw the Yucatán Peninsula regional initiative as a good example of the appropriate scale for REDD+, given the ecological and cultural similarities of the three peninsular states. The municipal officials stressed municipal land use planning as the cornerstone of any REDD+ actions. CONAFOR supports community level land use plans - they are, for example, one of the items on the "PEPY menu"-as well as the inter-municipal associations, conforming to watersheds and biological corridors [17]. The national Commission for the Development of Indigenous Peoples and Communities (CDI) runs its own program to promote strategic planning for rural development at the level of 'micro regions', consisting of five to six communities within a municipality and intended to 
result in development plans to be financed by governmental agencies in various sectors. While many of the same organizations sit in land use planning committees at the various levels as well as in the state REDD+ bodies and an inter-sectoral committee for the CDI program, none of the interviewees were able to articulate how the different planning processes were linked. It may be assumed that they are still implemented on parallel, independent tracks. It is not yet clear from the REDD+ policy documents, either, how the various planning processes add up at "territorial" scale and how and by whom territories will be defined, or whether they will be independently negotiated for each sub-national REDD+ intervention (cf. Mexico Emission Reductions Program Idea Note (ER-PIN): "the scale of the investment plan corresponds to a territory that includes a number of communities and ejidos and obeys an environmental limit (basin, sub-basin, biological corridor)" [17] (p. 33)).

While a holistic view of REDD+ was echoed by most actors, there was one group with contrasting views; community leaders, who would in the end be crucial actors in the implementation of REDD + at the local level. Over half the comisariados interviewed had heard of REDD+, but most were unclear on what it was. Some knew that it had to do with carbon, but they associated it with on-going Payments for Environmental Services programs, and assumed that "REDD" would be just another project for which they would solicit support from CONAFOR (i.e., on a piecemeal basis). This conception is not surprising - the project-by-project approach perpetuated by CONAFOR, including PEPY, has essentially subsidized most of their forest-related activities to date, so without information to the contrary, it is reasonable for comisariados to assume that REDD+ would be just another one of these projects. There is no evidence at all that this is what they would prefer, however. Interestingly, government representatives acknowledged that communities had this perception. Reasons for why comisariados, and most likely the communities that they represent as well, have been disconnected from the prevailing discourse on REDD+ are explored at the end of the following section.

In sum, it is clear that the dominant conceptualization of REDD + by the organizational actors (although not by the community leaders) as a transformative, holistic change towards rural sustainability at territorial scale embodies and accentuates requirements for effective horizontal as well as vertical integration in multilevel governance. Their arguments also suggest that the practices in earlier interventions, involving centralized planning and uncoordinated actions, do not match these requirements. Next, we discuss whether the structures and processes introduced for REDD + are contributing to the needed MLG transformation, or what challenges remain.

\subsection{Procedural Legitimacy in Horizontal and Vertical Coordination for REDD+}

\subsubsection{Participation and Representation in the Formal Structures and Networks}

As became evident during the sampling process, there was an extensive overlap between participation and/or having a role in the formal REDD+ structures such as the GT and CTC, and being nominated as organizational partners in information sharing and collaboration or as influential REDD+ actors. Two things may explain the overlap. The first is that the current structures (GT and CTC) integrate many actors with previous inter-organizational collaboration in forest management and nature conservation in the area. The second is that those linkages may have been strengthened as well as expanded to include new actors upon the introduction of the formal REDD+ planning bodies. 
Therefore, in the following we mainly focus on procedural legitimacy in the GT and CTC as the main nodes for horizontal and vertical integration for REDD+ governance in Quintana Roo.

Like the national GT-REDD+, the Quintana Roo GT is comprised of purely governmental actors: federal agencies CONAFOR, SAGARPA, the Ministry of Environment and the National Commission for Knowledge and Use of Biodiversity; the state government agencies for environment and agriculture; as well as the four AMUSUR municipalities. In addition, two NGOs, the national Consejo Civil Mexicano para la Silvicultura Sostenible and an alliance of NGOs known as Alianza REDD+, coordinated by The Nature Conservancy (TNC), form a technical advisory body for the GT. The GT was praised by several of its members for exemplifying good intersectoral cooperation backed by shared concerns about climate change.

Yet, the broader challenges of cross-sectoral integration for REDD+, evident in the above conceptualization of the problem, also apply here. In particular, two actors, both federal agencies, were mentioned as not sufficiently engaged with the REDD+ process although they should be: SAGARPA (despite being a GT member) and CDI (not a GT member). Although agreement about the importance of cross-sectoral coordination for sustainable rural development existed at the conceptual level, this had not yet been translated into joint planning and action. The interviewees described how strong existing institutional structures and practices resisted efforts to break out of the sectoral silos. For instance, when the local branches of federal agencies participate in state level planning, they are bound by their accountability towards the central offices, including meeting annual goals related to project implementation and disbursement of subsidies. This vertical, internal accountability thus sets the limits to their engagement with the state GT. The central agencies, for their part, operate within the sectoral hierarchies shaped by political priorities and power relations at the federal level. The short-term, project-based approaches were said to be determined by the Ministry of Finance, so even if local officials of, for example, CONAFOR acknowledged that they were inappropriate, there was little they could do to change the procedures.

As a result of the shifting priorities during the current administration, SAGARPA was seen as just short of abandoning the inter-sectoral climate change bodies. A specific convention to promote sectoral transversality had been signed between CONAFOR and SAGARPA in 2011 at the behest of the World Bank, a major funder of Mexico's Forest Investment Program, but the convention remained unimplemented. The Quintana Roo branch of CDI had participated in the consultation process for the regional REDD+ strategy in 2012, but had since "fallen out of the loop". Although accountability mechanisms exist to enforce cross-sectoral collaboration, participation out of mere institutional obligation - stated as the motivation for GT participation by the local SAGARPA representative - carries a risk. According to the interviewees, only formal deliverables, such as those currently used to evaluate project implementation ( $x$ number of workshops organized, or $y$ number of contracts signed) may be achieved by enforcement, but not the shared ownership over the process that is required to actually address the root causes of land use change and environmental degradation.

Still, the GT members emphasized its role as a learning experience, particularly in relation to the identification of REDD+ priority areas within Quintana Roo. The federal and state counterparts in agriculture, environment and forestry had jointly defined indicators for each of the three sectors to prioritize communities, later merged for a map of the most critical REDD + intervention areas. 
Although this exercise was carried out by the GT in apparent disconnect with, for instance, CONAFOR's prioritization of communities within PEPY, or the CTC, it was seen as an important first step towards improved state level inter-sectoral coordination.

Compared to the national CTC-REDD+, which had splintered out of the CTC for Payments for Environmental Services and was more of an open platform without membership and operational rules, the Quintana Roo CTC was a formal structure that had been introduced as part of the REDD+ Early Action by CONAFOR and the regional state governments. Perhaps as a bow towards the agriculture sector, and in line with defining REDD+ as rural development, representation in the Quintana Roo CTC was defined to follow the "product system" (Sistema Producto) model based in the Law for Sustainable Rural Development (2001). That is, each productive (sub) sector defines its representatives among different actors all along the value chain, from the primary producers to export companies. The product systems are validated by SAGARPA and recognized legally as a form of economic and social organization. In the Quintana Roo CTC, the sectors of agriculture (represented by the maize product system), livestock (beef), beekeeping, forestry, and "non-traditional products" (represented by the vanilla product system) had one vote each. Other segments of society had been similarly assigned a vote each: the private sector (represented by the hotel industry), educational and research organizations, as well as "the civil society sector" consisting of NGOs. In addition, there were individual members with voice but no vote, as well as an internally-elected president, vice-president and a technical secretary (the state environment agency SEMA). TNC also had an important role as the facilitator and supporter of the CTCs of all three peninsular states as well as the regional one.

Despite this formal, imposed form of organization, the NGOs that had been working in the area for a long time saw the CTC as a continuation of their previous efforts to collaborate in forestry and conservation, and later climate change and carbon issues. They also continued to form a more integrated group of collaborators on REDD+ than the product system representatives. As such, the CTC could be considered a mixed bunch of actors, some with their own long-term agenda in forests and climate change, others convened to the meetings much to their own surprise as the 'default members' resulting from the adoption of the product system representation model in the CTC:

"... he did not know he was there (in the CTC), but by default he was the member as the sector president. He did not know it but I explained it to him the other day when I sent the invitation. He said, something like that was mentioned before but I don't know what I'm going to do there. And he is totally right, I mean, how is it that I'm going to a meeting I've never been invited to before and how is my name there?" (CTC president, 2 December 2013).

Within the CTC, as a hybrid structure that merged a former issue network primarily consisting of NGOs with a government-promoted model for public participation that included new, assigned delegates, there were differing opinions about representation. One producer organization representative questioned the presence of NGOs, seeing them as opportunistic actors jumping at the chance to promote their agenda at any given venue but without really representing anyone but themselves, compared to the "democratic election of and solid support for" the product system representatives. But similarly, it may be questioned whether representation has been determined equally democratically within all the sectors, especially considering the heterogeneity of actors within the value chains. 
Small-scale producers may have very different means to participate and to have a say in such processes compared to typically well-connected and informed business actors. Some interviewees openly expressed concerns about their own challenges as sectoral representatives, such as finding time for convening meetings and motivating the participation of those they were supposed to represent. As described by one of them:

"I am already annoyed with convening meetings. I arrive there [in the meeting to discuss joint position for the CTC] and they almost do not attend, they are a few or they do not attend. I convene and I declare the meeting void. So I go with what I think I ought to say. So I am already participating as a person, although I represent six organizations. And I don't think I am the only one that this happens to" (Sectoral representative, 21 November 2013).

Furthermore, as the CTC is meant to come up with one combined vision to present to government (the consensus from non-government actors), CTC participants expressed concern at how consensus would be achieved when the wide variety of producers represented would likely have very different, and sometimes contrasting, interests (for example, the livestock and forestry representatives may not see eye to eye on REDD+ priorities).

While the CTC is comprised of organizations that are working with ejidos through a productive activity (timber, livestock, etc.), communities that are not part of any of these particular product-based associations are not represented, nor are any non-production focused community views. There is no system in place to organize local representation in the CTC through the communities' elected representative bodies, the comisariados, for instance. A gap in the local government system between the communities and municipalities was also pointed out by members of the producer organizations. Claiming that the municipalities were too far removed from what was happening on the ground, they argued that the producer organizations should be the principal interlocutor for the communities, as they had the most experience with them and understood local issues much better, despite the fact that these organizations work only with those communities that are engaged in commercial production of forest products.

The levels of participation in the CTC varied. The Quintana Roo CTC had had a dynamic start with several meetings in 2012, in comparison with, e.g., the Yucatán state CTC, where all REDD+ planning had slowed down after changes in the state government following 2012 elections. Yet the CTC Q. Roo meeting that the authors attended in December 2013 had been preceded by a long break, and for several members it was their first time to participate. Interviewed members explained the varying attendance or non-participation by the transaction costs of participation, which not only included physical attendance at the meetings and the related travel, as different towns alternated as the venue for the CTC, but also preparatory work. Lack of time-or to put it another way, prioritization of other tasks or agendas - explained absence or arriving at meetings unprepared, e.g., without revising any shared background documents beforehand. Some CTC members rather bitterly noted that while the governmental GT members could participate in REDD+ planning as part of their work duties and access resources for it (though the state government actors disputed this), the civil society members of the CTC were to cover both the time and travel costs by themselves.

Beyond the GT and CTC, we also observed tensions related to democratic representation regarding the AMUSUR, which paradoxically had been set up to address the problem of lack of continuity in 
municipal policies due to short local government periods [18]. Yet, the ink was barely dry on the inter-municipal convention signed in August 2013, when the municipal elections in October brought about staff changes and uncertainty about implementation. The federal and state facilitators of AMUSUR lamented the need to start all over again with the new municipal decision-makers and staff, who had not yet engaged with the GT at the time of the interviews and had varying levels of knowledge about what they, like the comisariados, referred to as "the REDD+ project". A source close to one of the member municipal governments suspected that contributions from municipal budgets to a trust fund under AMUSUR, the main envisioned means for channeling REDD+ funds to the local level, would be complicated in the current overall difficult financial situation, despite being mandated by the convention. As such, the AMUSUR experience will indeed be a test of how the lines of accountability and representation play out in efforts to coincide the idea of inter-municipal "territories" promoted by CONAFOR and foreign donors with existing jurisdictional structures, i.e., a democratically elected local government with a legal mandate to define its own priorities. Furthermore, the perceived disconnect between the municipalities and communities raises concerns about vertical coordination under the inter-municipal model.

\subsubsection{Information Sharing, Deliberation and Influence}

The role of the CTC as the main civil society counterpart of the GT was emphasized by several of the GT members. However, the relationship was described as a hierarchical one rather than exemplifying horizontal dispersion of power, with the GT leading the development of REDD+ proposals, later to be presented to and commented on by the CTC. Particularly prevalent among the more seasoned CTC participants that had long observed policy making at the state and federal levels was a sense of doubt about the role and influence of the CTC, partly explaining why these actors did not prioritize CTC participation. What exactly being a consultative body meant was summarized by one of them in this way:

"The only participatory body [in REDD+], but with limitations, is the Technical Consultative Council [CTC] which, as its name says, is consultative; that is, the decisions are made elsewhere" (Producer organization officer, 29 November 2013).

Other members shared the reservation that the CTC was only going to be used to "validate" whatever CONAFOR and the GT wished to propose, but still hoped that the CTC would eventually develop into an influential party to the REDD+ process:

"I would like it to be the Council [CTC], but traditionally and based on my experience, all the councils have been treated as something that you create to ensure that you are informing and listening to opinions, but as regards clear influence... Because as they (state and federal government representatives locally) say, if even we cannot influence this, then (how will) you?' That is, it all comes from Mexico City, the alignments come from Mexico City, so how to change them? For that it is difficult" (Director of a producer organization, 5 December 2013).

These observations draw attention to deliberative quality and distribution of power. The discussion in the CTC meetings up until December 2013 had largely revolved around operational rules and 
procedures. Discussions on substantive issues such as the draft national REDD+ strategy, what should be the content of the state REDD+ strategy, or various studies on the drivers of deforestation and forest degradation in Quintana Roo, had been repeatedly postponed. The low deliberative quality, or specifically, the continued focus on the procedures of the CTC as opposed to the content of REDD+, was partly explained by a kind of vicious circle. That is, the members of the CTC did not take the time to participate so that the procedures could be agreed upon by a sufficient quorum, or to read shared documents beforehand and hence be informed to debate about them, and then the same or other members got frustrated with the lack progress and influence, and did not participate in the next meeting. At the same time, the fact that the rules of operation within the CTC were self-defined by the members and the president and vice-president had been democratically elected was seen to support procedural legitimacy.

It was also suggested, however, that the CTC was not the arena to freely deliberate upon REDD+, which it was supposed to be, because the agenda was driven by external actors. Although the CTC was to function independently of the government, the technical secretary (SEMA) continued to convene the meetings. TNC had provided refreshments and a facilitator for the meetings. It was felt that since these actors had more information, they were able to control the discussion by proportioning relevant information. The government actors were said to respond defensively when questioned. Subtle dynamics of power relations and accountability then came to play, as described by one of the members:

"Now, the problem is, when somebody is financing you, there are also rights, and it is like... like you are afraid of contradicting the one who is paying, bringing the coffee. You feel like a traitor in a way. They are helping me and I'm telling them they are not giving me enough information" (Director of a producer organization, 5 December 2013).

The network analyses confirmed that influence (indegree centrality) as well as cross-scale brokerage positions for REDD+ information sharing were concentrated in the same few organizations of the REDD+ MLG system. In Figure 1, the network of REDD+ information sharing is visualized, indicating the types of organizations engaged at the different levels of governance, including the local communities and their information ties. According to the normalized indegree centrality measure (Figure 1), CONAFOR is the overall most influential organization, supporting the notion that REDD+ is still largely perceived as a CONAFOR initiative. SEMA is perceived influential at the state level. The state governments are in important positions for vertical and horizontal integration for REDD+ in the overall REDD + architecture [16,17], but they are dependent on federal and international support for any action, reducing their power. TNC has a strong regional as well as national presence. The same three organizations were also the most important cross-scale brokers of REDD+ related information. Although the deliberative quality in the CTC may be debated, structurally it is an important node for REDD+ information sharing especially for the new product system members, in comparison with the NGOs and forest producer organizations that also have other information ties (Figure 1).

Most of the community members/comisariados that were interviewed had had only indirect connections to the REDD+ processes. They recalled being at one of CONAFOR's workshops where the topic of REDD+ had been mentioned and briefly discussed, or had heard of the topic from their forestry organization representatives. However, lack of meaningful deliberation was evident in their lack of knowledge of what was going on with the CTC or the REDD+ process, as well as not 
understanding fully what REDD+ was about. These channels, thus, had not yet been effective in transferring information from the top-down or, for that matter, the bottom-up. NGO and academic interviewees commented that communities did not yet have an opinion to be heard, since they did not have sufficient information about REDD+ to opine on it. The reason for the disengagement of communities at this stage of planning and consultations was bluntly explained by the non-community interviewees: there was not much point in engaging communities now-since REDD + was not anything defined yet, why raise their expectations? And since information about REDD+ had barely reached the communities' leadership, it is clear (and this was also noted by many interviewees) that there had not yet been any consideration about different voices within the communities.

Figure 1. Cross-scale network of REDD+ information sharing. The ties represent relations in REDD+ information sharing. The direction of a tie (arrow) indicates direction of nomination; not all nominations were reciprocated. The perceived influence (normalized indegree centrality measure) of an actor is presented as the size of the node: the larger the node, the more influential the actor.

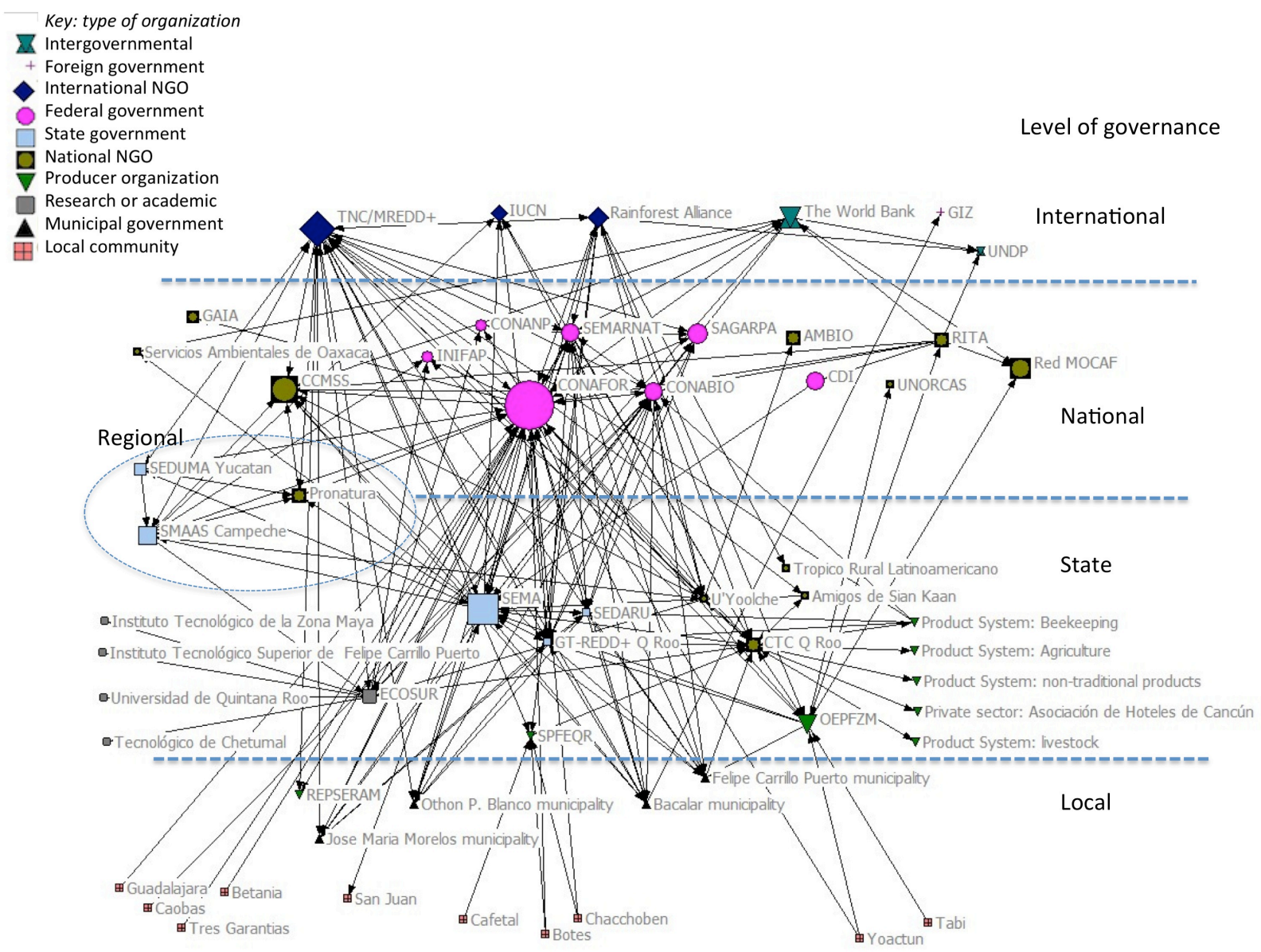

Community workshops had in fact been organized as part of consultations for the regional REDD+ strategy in 2012, but these were discounted by many as a hasty exercise implemented by a local university as a tightly scheduled consultancy. The NGO, producer organization and state government interviewees saw the selective information sharing at the local level, confined to sporadic workshops most often to disseminate calls for the different subsidy programs, as reinforcing a paternalistic system 
in which no real deliberative interaction to adapt actions to local circumstances takes place. In the diffusion fora (such as in PEPY), the centrally designed project options are announced to the producers, who then solicit whatever is on offer to access resources, although it may not be what is needed. The interviewed producer organization technicians and researchers had observed that people only expressed what they thought they were expected to say in such circumstances. The same actors were also frustrated with their own inability to provide insights into locally appropriate actions, despite their knowledge and experience. Fruitful deliberative exchanges with CONAFOR officials were said to be rare and entirely dependent on interpersonal relationships, but even those then had scant effects on program modalities given the internal hierarchies and sectoral lines of accountability. An example given was CONAFOR's continued focus on reforestation with nursery-grown seedlings with low survival rates once planted, while natural forest regeneration, demonstrated to be successful in the local conditions, was not recognized by the centrally designed programs. Thus people continued the ineffective reforestation activities as it provided a means to access subsidies.

\section{Conclusions}

The Mexican approach to REDD+, as outlined in the national policy documents, embodies specific requirements for multilevel governance, and the practice in Quintana Roo indicates that there is engagement of governmental and non-governmental organizations of a wide variety in the REDD+ planning bodies. As regards alignment of views, there is wide agreement among these actors with the envisioned policy approach that REDD + should take the form of a holistic, cross-sectoral, integrative strategy for sustainable rural development, and indeed many of the actors, as we have shown, contrasted this ideal with the current (inefficient, ineffective) situation in which projects are sector specific and standardized. Support was expressed for a territorial approach that could provide the basis for such integration, although there was uncertainty about how and by whom the territories would be defined. Importantly, the community leaders' understanding of REDD+ differed from this prevailing view. Although they were to some extent informed of the existence of REDD+, they were generally reliant on weak vertical information channels, and they perceived REDD+ as another CONAFOR program, which will involve communities individually applying for subsidies for forestry activities. Hence, the perspectives of the local community actors - whom the implementation of REDD + will ultimately depend on - on what sort of locally appropriate actions REDD+ would require in order to make a difference, and whether more holistic approaches as envisaged in the national strategy documents would be preferable to past approaches to forest management, have not yet been considered in the planning processes.

As regards procedural legitimacy, both horizontal as well as vertical coordination for REDD + is challenged by strong de facto centralized structures, despite legal decentralization of governance. The internal accountability of federal agencies limits state level cross-sectoral planning and action, and organizational hierarchies, determined by power relations as well as shifting political priorities, affect the buy-in of specific initiatives such as REDD+ across the sectors. More effective engagement of the agriculture sector - the 'big fish' among the Mexican rural development actors - remains a key challenge for implementing REDD + as a means to rural sustainability transition, especially while REDD+ is still strongly associated with a sub-sector agency lower in the organizational hierarchy 
(CONAFOR). Whether it would increase the chances of REDD+ success, as currently defined, if the national initiative was led by the formal head of the rural development field (SAGARPA) remains a normative as well as an empirical question beyond the scope of this study, which nevertheless highlights the role of higher level political buy-in of REDD+ for procedurally legitimate MLG processes.

On the vertical axis, participation, access to information and influence in the REDD+ process decrease towards the lower levels of governance. The most obvious gap in that regard is the current deliberate disengagement of the local communities beyond their productive sector representatives. By doing so, organizations working with communities intend to avoid false expectations and misconceptions about REDD+ as just another project, but may end up cultivating those in the absence of information to the contrary. The situation is not limited to the case of Quintana Roo but has been found in other Early Action Areas in Mexico, in Jalisco, for example [49]. While REDD+ requires a national approach to the carbon accounting, implementing REDD+ top-down through centrally designed actions, as in the current REDD+ Early Action efforts, compromises both mechanisms through which procedurally legitimate MLG might improve REDD+ effectiveness: ownership through inclusive participation in the planning and decision making, as well as social learning for improved institutional fit and locally appropriate actions. Given that communities are the rights holders of much of the land and forests in this region, it is clear that their views need to be much more clearly solicited if REDD+ is to be effective. The disengagement, to date, of communities in the REDD+ process, and continued perceptions of an overly centralized system, is somewhat surprising, given that communities are the clear rights holders in Mexico. This situation does not bode well for REDD+ processes in the many countries where communities' rights are much less secure.

The Yucatán Peninsula state governments have assumed ownership over the REDD+ processes and are actively leading the development of their own strategies, offering a window to incorporate at least regional, if not fully local perspectives. Yet, they remain unable to implement significant actions without federal support.

At the broad level, the discursive agreement among various actors on the 'right way to go' may be seen as a major opportunity not only for REDD+, but effective natural resource MLG in general. Concrete efforts should be aligned with the envisioned approach, including more equal distribution of resources and influence across the horizontal and vertical axis of the REDD+ MLG system. At the moment, it appears that the REDD+ structures are designed without sufficient attention to the past histories of participation and interaction between different levels of governance and the civil society. Horizontal dispersion of power would also entail balancing the roles of the GT and the CTC, so that the transaction costs of participation combined with weak deliberative quality and influence on the REDD+ process do not compromise the legitimacy of the CTC. A more prominent role of the CTC in defining REDD+ 'territories' and in steering the pilot actions might work to increase the feeling of useful and consequential participation, and subsequently the motivation by diverse actors to contribute their expertise to social learning processes for the development of locally appropriate actions. Specific attention has to be dedicated to resolving the issues of representation and accountability in the CTC, especially concerning the participation of local communities, so that a balance in the integration of issue-specific networks with democratic governance structures is achieved. 


\section{Acknowledgments}

The work was undertaken with support from the Academy of Finland and the Social Sciences and Humanities Research Council of Canada. We remain grateful to all the participants of this study for their valuable contributions and insights.

\section{Author Contributions}

Salla Rantala designed the research with inputs from Margaret Skutsch and Reem Hajjar. Salla Rantala and Reem Hajjar collected and analyzed the data. Salla Rantala, Reem Hajjar and Margaret Skutsch wrote the paper.

\section{Conflicts of Interest}

The authors declare no conflict of interest.

\section{References}

1. Global Landscapes Forum. GLF Policy Recommendation 1: Negotiators should apply landscape approach principles to REDD+. Available online: http://www.landscapes.org/glf-policyrecommendation-1-negotiators-apply-landscape-approach-principles-redd/ (accessed on 7 August 2014).

2. Pacheco, P.; Aguilar-Støen, M.; Börner, J.; Etter, A.; Putzel, L.; Diaz, M.; del, C.V. Landscape transformation in tropical Latin America: Assessing trends and policy implications for REDD+. Forests 2010, 2, 1-29.

3. Van Noordwijk, M.; Minang, P.A.; Dewi, S.; Hall, J.; Rantala, S. Reducing Emissions from All Land Uses (REALU): The case for a whole landscape approach. ASB Policy Brief 2009, 13, 1-4.

4. Kashwan, P.; Holahan, R. Nested governance for effective REDD+: Institutional and political arguments. Int. J. Commons 2014, 8, 554-575.

5. Visseren-Hamakers, I.; Verkooijen, P. The practice of interaction management: Enhancing synergies among multilateral REDD+ institutions. In Forest and Nature Governance; Arts, B., Behagel, J., Bommel, S., van Koning, J., de Turnhout, E., Eds.; Springer: Wageningen, The Netherlands, 2013; pp. 133-149.

6. Bache, I.; Flinders, M. Multi-Level Governance; Oxford University Press: Oxford, UK, 2004.

7. Piattoni, S. Multi-level governance: A historical and conceptual analysis. J. Eur. Integr. 2009, 31, 163-180.

8. Pahl-Wostl, C. A conceptual framework for analysing adaptive capacity and multi-level learning processes in resource governance regimes. Glob. Environ. Chang. 2009, 19, 354-365.

9. Mwangi, E.; Wardell, A. Multi-level governance of forest resources. Int. J. Commons 2012, 6, 79-103.

10. Peters, B.G.; Pierre, J. Multi-level governance and democracy: A Faustian bargain? In Multi-Level Governance; Bache, I., Flinders, M., Eds.; Oxford University Press: Oxford, UK, 2004; pp. 75-89. 
11. Young, O.R. The Institutional Dimensions of Environmental Change: Fit, Interplay, and Scale; MIT Press: Cambridge, MA, USA, 2002.

12. Newig, J.; Fritsch, O. Environmental governance: Participatory, multi-level and effective? Environ. Policy Gov. 2009, 19, 197-214.

13. Brockhaus, M.; Angelsen, A. Seeing REDD+ through 4Is: A political economy framework. In Analysing REDD+: Challenges and Choices; Angelsen, A., Brockhaus, M., Sunderlin, W.D., Verchot, L., Eds.; Center for International Forestry Research (CIFOR): Bogor, Indonesia, 2012; pp. 15-30.

14. Papadopoulos, Y. Problems of democratic accountability in network and multilevel governance. Eur. Law J. 2007, 13, 469-486.

15. SEMARNAT. Mexico's Vision for REDD+: Towards a National Strategy; Secretaria de Medio Ambiente y Recursos Naturales: Mexico City, Mexico, 2010.

16. CONAFOR. Estrategia Nacional Para REDD+ (ENAREDD+); Comisión Nacional Forestal: Guadalajara, Mexico, 2013.

17. CONAFOR. Mexico Emission Reductions Program Idea Note (ER-PIN); Forest Carbon Partnership Facility (FCPF), Carbon Fund: Washington, DC, USA, 2014.

18. CONAFOR. Modelo de gobernanza intermunicipal REDD+. Available online: http:// www.conafor.gob.mx/web/temas-forestales/bycc/acciones-de-preparacion-para-redd/modelo-degobernanza-intermunicipal-redd/ (accessed on 27 May 2014).

19. Beisheim, M.; Dingwerth, K. Procedural Legitimacy and Private Transnational Governance Are the Good Ones Doing Better; SFB 700: Berlin, Germany, 2008.

20. Scharpf, F.W. Legitimacy in the multi-actor European polity. In Organizing Political Institutions. Essays for Johan P. Olsen; Egeberg, M., Lægreid, P., Eds.; Scandinavian University Press: Oslo, Norway, 1999; pp. 261-288.

21. Kronsell, A.; Bäckstrand, K. Rationalities and Forms of Governance: A Framework for Analysing the Legitimacy of New Modes of Governance. In Environmental Politics and Deliberative Democracy: Examining the Promise of New Modes of Governance; Bäckstrand, K., Khan, J., Kronsell, A., Lovbrand, E., Eds.; Edward Elgar Publishing: Cheltenham, UK/Northampton, MA, USA, 2010; pp. 28-46.

22. United Nations Framework Convention on Climate Change. In Proceedings of the Report of the Conference of the Parties on its Sixteenth Session, Cancun, Mexcio, 29 November-10 December 2010.

23. Fischer, F.; Forester, J. The Argumentative Turn in Policy Analysis and Planning; Duke University Press: Durham and London, UK, 1993.

24. Hajer, M.A.; Wagenaar, H. Deliberative Policy Analysis: Understanding Governance in the Network Society; Cambridge University Press: Cambridge, UK, 2003.

25. Manin, B. On legitimacy and political deliberation. Polit. Theory 1987, 15, 338-368.

26. Arts, B.; Buizer, M. Forests, discourses, institutions: A discursive-institutional analysis of global forest governance. For. Policy Econ. 2009, 11, 340-347.

27. Rantala, S.; di Gregorio, M. Multistakeholder environmental governance in action: REDD+ discourse coalitions in Tanzania. Ecol. Soc. 2014, 19. Available online: http://eprints.whiterose. ac.uk/id/eprint/80126 (accessed on 15 September 2014). 
28. Keohane, R.O. Global Governance and Democratic Accountability; Oxford University Press: New York, UK, 2003; pp. 1-35.

29. Laumann, E.-O.; Marsden, P.-V.; Prensky, D. The boundary specification problem in network analysis. In Research Methods in Social Network Analysis; Freeman, L.C., White, D.R., Romney, A.K., Eds.; Transaction Publishers: New Brunswick, NJ, USA, 1992; pp. 61-709.

30. Carrington, P.J.; Scott, J.; Wasserman, S. Models and Methods in Social Network Analysis; Cambridge University Press: Cambridge, UK, 2005.

31. Laumann, E.O.; Marsden, P.V.; Galaskiewicz, J. Community-elite influence structures: Extension of a network approach. Am. J. Sociol. 1977, 83, 594-631.

32. Costenbader, E.; Valente, T.W. The stability of centrality measures when networks are sampled. Soc. Netw. 2003, 25, 283-307.

33. Fernandez, R.M.; Gould, R.V. A dilemma of state power: Brokerage and influence in the national health policy domain. Am. J. Sociol. 1994, 99, 1455-1491.

34. Ernstson, H.; Barthel, S.; Andersson, E.; Borgström, S.T. Scale-crossing brokers and network governance of urban ecosystem services: The case of Stockholm. Ecol. Soc. 2010, 15, 28.

35. Corbera, E.; Estrada, M.; May, P.; Navarro, G.; Pacheco, P. Rights to land, forests and carbon in REDD+: Insights from Mexico, Brazil and Costa Rica. Forests 2011, 2, 301-342.

36. Cronkleton, P.; Bray, D.B.; Medina, G. Community forest management and the emergence of multi-scale governance institutions: Lessons for REDD+ development from Mexico, Brazil and Bolivia. Forests 2011, 2, 451-473.

37. CONAFOR. Proceso Nacional REDD+: F. Participación. Available online: http://www.conafor.gob. mx/portal/index.php/proceso-nacional-redd/f-participacion (accessed on 7 October 2013).

38. SAGARPA. El presupuesto 2014 de SAGARPA se invertirá para impulsar la productividad agroalimentaria. Secretaría de Agricultura, Ganadería, Desarrollo Rural, Pesca y Alimentación, Mexico City, Mexico. Available online: http://sagarpa.gob.mx/saladeprensa/2012/Paginas/ 2014B009.aspx (accessed on 2 February 2014).

39. Secretaría de Hacienda y Crédito Público. Presupuesto de Egresos de la Federación para el Ejercicio Fiscal 2014. Available online: http:/www.shcp.gob.mx/EGRESOS/PEF/Paginas/ DocumentosRecientes.aspx (accessed on 2 April 2014).

40. Alix-Garcia, J.; McIntosh, C.; Sims, K.R.E.; Welch, J.R. The ecological footprint of poverty alleviation: Evidence from Mexico's Oportunidades program. Rev. Econ. Stat. 2013, 95, 417-435.

41. Busch, C.B.; Vance, C. The diffusion of cattle ranching and deforestation: prospects for a hollow frontier in Mexico's Yucatán. Land Econ. 2011, 87, 682-698.

42. Vance, C.; Geoghegan, J. Temporal and spatial modelling of tropical deforestation: A survival analysis linking satellite and household survey data. Agric. Econ. 2002, 27, 317-332.

43. Klepeis, P.; Vance, C. Neoliberal policy and deforestation in Southeastern Mexico: An assessment of the PROCAMPO Program. Econ. Geogr. 2003, 79, 221-240.

44. Abizaid, C.; Coomes, O.T. Land use and forest fallowing dynamics in seasonally dry tropical forests of the southern Yucatán Peninsula, Mexico. Land Use Policy 2004, 21, 71-84.

45. Radel, C.; Schmook, B.; Chowdhury, R.R. Agricultural livelihood transition in the southern Yucatán region: Diverging paths and their accompanying land changes. Reg. Environ. Chang. 2010, 10, 205-218. 
46. Schmook, B.; Radel, C. International labor migration from a tropical development frontier: Globalizing households and an incipient forest transition. Hum. Ecol. 2008, 36, 891-908.

47. Ellis, E.A.; Porter-Bolland, L. Is community-based forest management more effective than protected areas? A comparison of land use/land cover change in two neighboring study areas of the Central Yucatan Peninsula, Mexico. For. Ecol. Manag. 2008, 256, 1971-1983.

48. CONAFOR. Apoyos 2013: Lineamientos de Operación para el Programa Especial para la conservación, restauración y el manejo sustentable de los recursos forestales de la Península de Yucatán (PEPY). Available online: http://www.conafor.gob.mx/portal/index.php/tramites-yservicios/apoyos-2013 (accessed on 28 May 2014).

49. Skutsch, M.; Borrego, A.; Morales-Barquero, L.; Paneque-Gálvez, J.; Salinas-Melgoza, M.; Ramirez, M.I.; Perez-Salicrup, D.; Benet, D.; Monroy, S.; Gao, Y. Opportunities, constraints and perceptions of rural communities regarding their potential to contribute to forest landscape transitions under REDD+: Case studies from Mexico. Int. For. Rev. in press.

(C) 2014 by the authors; licensee MDPI, Basel, Switzerland. This article is an open access article distributed under the terms and conditions of the Creative Commons Attribution license (http://creativecommons.org/licenses/by/4.0/). 